stimulation or water can be altered systematically by varying the intensity of the stimulating current.

The administration of the two drugs produced a marked change in the preference for hypothalamic stimulation and water. Statistical analyses demonstrated that the number of lever presses for hypothalamic stimulation was increased by amphetamine and reduced by phenobarbital (Series 1: $\lambda^{2} r=8, p<.02$; Series $2: \lambda^{2} r=6, p<.05$ ), whereas the number of lever presses for water was reduced by amphetamine and increased by phenobarbital (Series 1: $\lambda^{2} \mathrm{r}=8, \quad \mathrm{p}<.02 ; \quad$ Series $2 ; \quad \lambda^{2} \mathrm{r}=6.5$, $p<.05)$. Superficially, the change in preference appears to be somewhat greater for the animals in Series 1 than for those in Series 2 , but this is due mainly to the duration of stimulation being shorter $(0.2 \mathrm{sec}$ as compared to $0.5 \mathrm{sec})$ so that there was more opportunity for the animals in Series 1 to press the lever which controlled the hypothalamic stimulation.

The electrodes were in the lateral hypothalamus between A 4.6 and A 5.2. They were in the medial forebrain bundle either near the fornix or as much as $1 \mathrm{~mm}$ lateral to the fornix.

\section{DISCUSSION}

It has been reported that rats will self-stimulate the lateral hypothalamus and neglect basic needs for survival (Morgan \& Mogenson, 1966; Routtenberg \& Lindy, 1965; Spies, 1965). When the current intensity is optimal for self-stimulation, the motivation for seeking water by pressing a lever is weaker than the motivation-reinforcement consequences of pressing a lever to stimulate the lateral hypothalamus; the animal self-stimulates the hypothalamus and ignores the water lever (Morgan \& Mogenson, 1966). If the current intensity is reduced (see Table 1, control) or if the water is made more palatable by the addition of saccharin, glucose, or sucrose (Phillips, Morgan, \& Mogenson, 1968), the animal switches from the lever that delivers hypothalamic stimulation of optimal intensity to the one that delivers the liquid reward. Apparently, an animal's preference in these tests is a function of the relative strengths of the motivation-reinforcement consequences associated with the two levers.

In the present study, the preference behavior was changed, presumably because the two drugs employed influenced the motivation-reinforcement consequences of pressing the two levers. Amphetamine has been shown to increase the reinforcement of hypothalamic stimulation (Mogenson, 1968; Stein, 1964) and to decrease the motivation to drink water when it is elicited by deprivation (Epstein, 1959) or by electrical stimulation of the lateral hypothalamus (Mogenson, 1968). Therefore, the animal's preference shifts because of reduced motivation for water reward coupled with an enhanced motivation for hypothalamic stimulation. On the other hand, for phenobarbital, which has little, if any, effect on self-stimulation of the hypothalamus(Olds, Killam, \& Eiduson, 1957), the change in preference is apparently due to its enhancing the motivation for water (Mogenson, McLachlan, Wishart, \& Stevenson, 1969; Schmidt, 1964). Apparently, amphetamine and phenobarbital both influence the integrative-control mechanisms for the regulation of water balance, whereas amphetamine, but not phenobarbital, influences the mechanisms that subserve brain self-stimulation.

\section{REFERENCES}

EPSTEIN, A. N. Suppression of eating and drinking by amphetamine and other drugs in normal and hyperphagic rats. Journal of Comparative \& Physiological Psychology, 1959, 52, 37-45.

MOGENSON, G. J. Effects of amphetamine on self-stimulation and induced drinking. Physiology \& Behavior, 1968, 3, 133-136.

MOGENSON, G. J., MCLACHLAN, R., WISHART, T., \& STEVENSON, J. A. F. Effects of phenobarbital on water intake of rats with lesions of the ventromedial hypothalamus or septum. Federation Proceedings, 1969, 28, 648 .

MOGENSON, G. J., \& STEVENSON, J. A. F. Drinking and self-stimulation with electrical stimulation of the lateral hypothalamus. Physiology \& Behavior, 1966, 1, 251-254.
MORGAN, C.W., \& MOGENSON, G. J. Preference of water-deprived rats for stimulation of the lateral hypothalamus rather than water. Psychonomic Science, 1966, 6, 337-338.

OLDS, 3., KILLAM, K. . ., \& EIDUSON, S. liffects of tranquilizers on self-stimulation of the brain. In S. Garettinj and V. Ghetti, (Eds.) Psychotropic drugs. New York: Elsevier, 1957 Pp. 235-243.

PHILLIPS, A. G., MORGAN, C. W., \& MOGENSON, G. J. Brain stimulation versus water, saccharin or sucrose in food and water deprived rats. Paper presented at Eastern Psychological Association, Washington, D.C. April 1968.

ROUTTENBERG, A., \& LINDY, J. Effects of availability of rewarding septal and hypothalamic stimulation on bar pressing for food under conditions of deprivation. Journal of Comparative \& Physiological Psychology, $1965,60,158-161$

SCHMIDT, H. Water intake as an index of drug action. In W. J. Wayner, (Ed.), Thirst. New York: Pergamon Press, 1964.

SPIES, G. Food versus intracranial self-stimulation reinforcement in food-deprived rats. Journal of Comparative \& Physiological Psychology, 1965 , 60, 153-157.

STEIN, L. Self-stimulation of the brain and the central action of amphetamine. Federation Proceedings, 1964, 23, 836-849.

TEITELBAUM, P., \& DERKS, P. The effect of amphetamine on forced drinking in the rat Joumal of Comparative \& Physiological Psychology, 1958, 51, 801-810.

\section{NOTE}

1. Research was supported by grants from the MRC and the NRC of Canada. The technical assistance of Mrs. Mary Dinning and the suggestions of Mr. A. G. Phillips during the preparation of the manuscript are gratefully acknowledged.

\title{
Length of sleep and length of waking interrelations in the rat ${ }^{1}$
}

\section{$W I L S E \quad B$. WEBB and JOYCE FRIEDMANN, University of Florida, Gainesville, Fla. 32601}

Across a $24 h$ period in a confined $E E G$ recording setting, the length of successive sleep and waking episodes in the rat showno direct relationship. These data imply a limitation to a hypothesis of sleep as a simple energy restoration or storage period.

A simple but impelling hypothesis about the function of sleep is that it serves as a period of energy storage or restoration. The sleep period may serve, under such a hypothesis, to dispose of accumulated toxins, restore depleted energy or develop and store energy for expenditure during waking, or serve a combination of these functions. From such a model, it would follow that the energy expenditure during the waking period would predict the length of the subsequent sleep period or, if the sleep period was an energy development and storage state, the length of the sleep period would predict the energy expenditure of the subsequent wake period. If the amount of energy expenditure during the waking periods was essentially equal, then the length of the waking period would be predictable from the sleep period, or vice versa.

For the purpose of exploring these predictions, the sleep of the laboratory rat provides an ideal paradigm. The rat's sleep and waking is quite episodic across a $24-\mathrm{h}$ period, with widely varying lengths of these episodes. For the nine animals reported in this study, the mean number of episodes of sleep was 67.0 , with a range from 45 to 87 
Table 1

Lengths of Wake Episodes Followed by Lengths of Sleep Episodes and Sleep Episodes Followed by Wake Episodes

\begin{tabular}{|c|c|c|c|c|c|c|c|c|}
\hline & \multicolumn{4}{|c|}{$\begin{array}{l}\text { Closed Linvironment } \\
\mathrm{N}=5\end{array}$} & \multicolumn{4}{|c|}{$\begin{array}{l}\text { Open Environment } \\
\mathrm{N}=4 \\
\end{array}$} \\
\hline & \multicolumn{2}{|c|}{ Light Period } & \multicolumn{2}{|c|}{ Dark Period } & \multicolumn{2}{|c|}{ Light Period } & \multicolumn{2}{|c|}{ Dark Period } \\
\hline & W-S* & $S-W^{* *}$ & W-S & S-W & W-S & S-W & W-S & S-W \\
\hline short-short & 11 & 17 & 21 & 22 & 14 & 11 & 18 & 13 \\
\hline long-long & 16 & 12 & 21 & 22 & 7 & $1 \hat{1}$ & 17 & 20 \\
\hline medium-medium & 17 & 14 & 27 & 30 & 11 & 13 & 14 & 13 \\
\hline short-medium & 20 & 9 & 24 & 25 & 8 & 8 & 13 & 16 \\
\hline medium-short & 15 & 17 & 23 & 26 & 5 & 11 & 14 & 19 \\
\hline long-medium & 10 & 19 & 26 & 18 & 10 & 8 & 20 & 7 \\
\hline medium-long & 12 & 14 & 25 & 25 & 13 & 4 & 20 & 13 \\
\hline short-long & 18 & 14 & 25 & 23 & 10 & 11 & 12 & 14 \\
\hline long-short & 18 & 16 & 26 & 27 & 12 & 9 & 12 & 11 \\
\hline
\end{tabular}

* Wake followed by sleep

** Sleep followed by wake

Table 2

\begin{tabular}{|c|c|c|c|c|c|c|}
\hline & \multicolumn{2}{|c|}{ Dark } & \multicolumn{2}{|c|}{ Light } & \multirow[b]{2}{*}{ W-S } & \multirow[b]{2}{*}{$S-Y$} \\
\hline & W-S & $S-W$ & W-S & S-W & & \\
\hline $\begin{array}{l}\text { short-short } \\
\text { long-long }\end{array}$ & 48 & 51 & 77 & 77 & 125 & 128 \\
\hline $\begin{array}{l}\text { short-long } \\
\text { long-short }\end{array}$ & 58 & 50 & 75 & 75 & 133 & 12 \\
\hline
\end{tabular}

episodes. The sleep periods varied in length from $1 \mathrm{~min}$ to $105 \mathrm{~min}$, and the waking periods varied from $2 \mathrm{~min}$ (a criterion imposed by the Es) to $82 \mathrm{~min}$ in length. Furthermore, the energy expenditure during the waking period could be considered essentially low and homogeneous. Recordings were done in relatively confined recording areas, with no variation in stimulation or specific task demands.

The purpose of this study was to determine if the length of the waking periods and the length of the sleeping periods were successively interrelated.

\section{METHOD}

Nine male Long-Evans strain rats were implanted stereotaxically with bipolar steel recording electrodes in the hippocampus, and with two cortical screws placed unilaterally over frontal and parietal areas. These were crimped into amphenol miniconnector pins embedded in a plastic block that was chronically cemented to the skull. After surgery, there was at least a 1-week recovery period and a 1-week habituation to the recording situation. Ss were recorded in $18 \mathrm{~cm}$ (deep) $\times 18 \mathrm{~cm}$ (diam) plastic canisters. Food and water were available at all times. At 140 days of age, electroencephalogram recordings were obtained for 24-h periods. The records were visually scored in 1-min units as either wake, sleep, or paradoxical sleep.

For other experimental purposes, the animals had been raised since weaning in the attached cage of Wohlmann activity wheels $(25 \times 15 \times 12 \mathrm{~cm}$ area). Four of the Ss had access to the activity wheel at all times; five were restricted to the cage area. These groups are reported separately.

The animals were raised under a $12-\mathrm{h}$ light/12-h dark regime.

\section{RESULTS}

The relative lengths of the sleep and waking episodes differed considerably between Ss and between dark and light periods. Furthermore, the individual $S$ 's periods were variously skewed. For the purposes of analyses, each animal's sleep and waking periods were separately ranked, relative to length, and divided into thirds of sleep and waking length. For each animal, each episode was then designated as "short," "medium," or "long." Beginning with the first wake episode, and serially across the $24 \mathrm{~h}$, each wake period (coded as "short," "medium," or "long") was tallied in terms of the coded characteristic of the succeeding sleep period. This was then done for each sleep period beginning with the first sleep period. These tallies were done by the two separate rearing conditions and by light and dark periods. These results are reported in Table 1 . Table 2 presents summary statistics derived from Table 1. None of the columns or combinations of the two tables result in a significant $\chi^{2}$.

In simple summary of these tables, a sleep period of a given coded length (short, medium, or long) had an equal probability of being followed by a period which was short, medium, or long. Similarly, a wake period of a given length had an equal probability of being followed by a period of the same length or the other two coded lengths. This was true during either light conditions or dark conditions.

DISCUSSION AND CONCLUSIONS

During a 24-h period, under circumstances in which there is no stimulus demands on the length of the waking or sleep periods (other than diurnal periodicity), the length of these episodes varies widely. The hypothesis that the sleep period is a simple and direct energy restoration or storage period is not sustained by the data of this report. These data do not speak to circumstances of high or sustained energy demands. Indeed, there is evidence that such conditions do affect the quality of the sleep response (Baekland \& Lasky, 1968; Hobson, 1968; Matsumoto et al, 1968). Furthermore, even in this limited situation, there may be complex "entrainments" of the sleep and waking responses reflecting an energy-sleep relationship (although we have not yet been able to decipher them). However, in this "free-running" and low-energy-demand paradigm, we must seek bases other than period length or a simple energy expenditure output for prediction of sleep and waking period lengths.

\section{REFERENCES}

BAEKLAND, F., \& LASKY, L. Exercise and sleep patterns in college athletes. Perceptual \& Motor Skills, 1966, 23, 1203-1207.

HOBSON, J. Sleep after excercise. Science, 1968, $162,1503-1505$.

MATASUMOTO, J., NISHISHO, T., SUTO, T., SADAHIRO, T., \& MIYOSHI, M. Effects of fatigue on sleep. Nature, $1968,218,177-178$. NOTE

1. These data were presented at the Association for the Psychophysiological Study of Sleep in Boston, March 1969. This study was supported by USPHS Grant M-3881. We are grateful to Drs. Allan Rechtshaffen and Allan Hobson for their comments without attributing responsibility to them for the contents of this report. 